\title{
Applications of Managerial Economics in Business Pricing Strategies
}

\author{
Yunhao $\mathrm{Ke}^{1^{*}}$ \\ ${ }^{1}$ Wuhan Britain-China School, China, 430000
}

\begin{abstract}
Pricing Strategies are crucial determinants of business success in terms of sales revenue and profitability. This article introduces some key concepts in managerial economics such as price bundling that have significant applications in sophisticated business pricing. The concepts are illustrated separately through detailed theory explanation with graphical analysis, and a real-life business case is briefly discussed for each of these concepts to demonstrate the practical applications of the theoretical ideas. It can be concluded that although some limitations have to be taken into account, these ideas still provide essential insights into the pricing process and can effectively improve firms' profit conditions.
\end{abstract}

\section{INTRODUCTION}

Managerial Economics is a science that utilizes economic theories and tools to facilitate business management and assist in practical decision-making processes. Under its guidance, business managers can use their rational senses to effectively allocate scarce resources, make strategic decisions, achieve the business objective of profit-maximization, and obtain sustainable growth in the market.

As one of the most crucial factors in business activities, price determines a company's sales volume and reflects its ability to generate profit, take advantage of consumer demand, and settle competition in the market. Therefore, a reasonable pricing strategy is indispensable for business success. However, numerous business managers neglect some essential techniques in the pricing process and simply adopt cost-plus pricing, which cannot flexibly respond to the dynamic demand conditions, and competition or fully unlock the profit potential. "The moment you make a mistake in pricing, you're eating into your reputation or your profits." As a result, it is an urgent task for managers to design an optimum pricing strategy in accordance with their business objectives.

Hopefully, theories of managerial economics may provide some key insights into such strategies. It can be demonstrated by abundant cases that managerial economics approaches can help businesses to confront with practical challenges, analyze their situations, and improve their pricing methods. Several applications of managerial economics concepts will also be discussed to illustrate the rationale in which optimum pricing could be achieved.

\section{ESSENTIAL MANAGERIAL ECONOMICS IDEAS IN THE PRICING PRocess}

\section{A.Price Bundling}

1) Theory Explanation: Price bundling occurs when a firm provides several products together as a package to its consumers with a bundle price generally lower than that purchasing them separately. A conventional practice of bundling is the set menu in which starters, main courses, drinks, and desserts are offered together at a single discounted price. Themes parks also sell a bundle of tickets for individual themes and toothbrushes are often bundled with toothpastes, attracting consumers to buy a set of goods at once.

The rationale for bundling isn't complicated. Bundling would be necessary for the complementarity of the products, as the bundle of products works more efficiently together than alone. For the purpose of cost-saving, bundling several products together will be cheaper for firms to sell as the marketing costs and distribution costs are truncated, thus obtain potential economics of scale. And from a Managerial Economics perspective, it can capture a larger amount of consumer surplus (the net gain to consumers for purchasing the goods) in the market to enhance the firms, profitability substantially.

To begin with the analysis, the reservation price is first defined as the maximum price that a consumer is willing to pay for a product. For simplicity, the marginal costs of producing the products is ignored to focus on revenue-maximization, and firms can assume that the reservation price for the bundles is exactly the sum of that for the individual products. Suppose there are two groups of consumers containing 100 members in the

\footnotetext{
* Corresponding author: jace_jkrsn@163.com
} 
market and their reservation prices for the firm' $s$ two products are shown below in the table.

TABLE I. DIFFERENT RESERVATION PRICES FOR PRODUCT 1\&2

\begin{tabular}{|c|c|c|}
\hline Groups of Consumers & Reservation Price for product 1 (\$) & Reservation price for product 2 (\$) \\
\hline Group A & 60 & 100 \\
\hline Group B & 100 & 60 \\
\hline
\end{tabular}

The total revenue of the firm could be expressed as $\mathrm{TR}=\mathrm{P} 1 * \mathrm{Q} 1+\mathrm{P} 2 * \mathrm{Q} 2$, where $\mathrm{Q} 1$ and $\mathrm{Q} 2$ depend on the relations between the selling prices and reservation prices of the products. Through careful calculations, firms could determine that the optimum price for both products is $\$ 60$ and the maximized total revenue would be $\$ 24000$. However, there are still sufficient amounts of consumer surplus to be extracted, as Group A consumers will be willing to pay more than $\$ 60$ for product 2 and Group B consumers have a higher reservation price than $\$ 60$.

TABLE II. QUANTITY SOLD AND REVENUE FOR THE FIRM IN THE UNBUNDLED CASE

\begin{tabular}{|c|c|c|c|c|c|c|}
\hline P1(\$) & P2(\$) & $\begin{array}{c}\text { Relations between } \\
\text { P1 and R1 }\end{array}$ & $\begin{array}{c}\text { Relations between } \\
\text { P2 and R2 }\end{array}$ & Q1 & Q2 \\
\hline 60 & 60 & $\mathrm{P} 1=\mathrm{R} 1 \mathrm{~A}<\mathrm{R} 1 \mathrm{~B}$ & $\mathrm{P} 2=\mathrm{R} 2 \mathrm{~B}<\mathrm{R} 2 \mathrm{~A}$ & 200 & 200 \\
\hline 60 & 100 & $\mathrm{P} 1=\mathrm{R} 1 \mathrm{~A}<\mathrm{R} 1 \mathrm{~B}$ & $\mathrm{R} 2 \mathrm{~B}<\mathrm{P} 2=\mathrm{R} 2 \mathrm{~A}$ & 200 & 100 \\
\hline 100 & 60 & $\mathrm{R} 1 \mathrm{~A}<\mathrm{P} 1=\mathrm{R} 1 \mathrm{~B}$ & $\mathrm{P} 2=\mathrm{R} 2 \mathrm{~B}<\mathrm{R} 2 \mathrm{~A}$ & 100 & 24000 \\
\hline 100 & 100 & $\mathrm{R} 1 \mathrm{~A}<\mathrm{P} 1=\mathrm{R} 1 \mathrm{~B}$ & $\mathrm{R} 2 \mathrm{~B}<\mathrm{P} 2=\mathrm{R} 2 \mathrm{~A}$ & 100 & 2000 \\
\hline
\end{tabular}

Bundling effectively addresses that problem. If firms charge a total of $\$ 160$ for a bundle of product 1 and product 2 instead of pricing them separately, the quantity demanded of the bundle will be exactly 200 as the reservation price of the bundle is the same between the two groups. The enhanced total revenue will, therefore, be $\$ 32000$, approximately one-third more than the previous value. This stunning increase in profitability that price bundling generates could be explained by the negative correlation across customers, as "some customers have higher reservation prices for one item in the bundle but lower reservation prices for another item in the bundle, whereas another group of customers has the reverse preferences." [1]. As long as this heterogeneity of reservation prices exists among consumers, bundling is a preferable strategy even if firms don' t have the information on the individual reservation prices and cannot adopt evident price discrimination.

2) An Application of Bundling: In Fall 1988, Microsoft, the behemoth in the software industry, offered an option for consumers to purchase some of its application programs as a "suite". The price of the suite of the four types of programs--spreadsheet, wordprocessor, graphics, and database--was less than half of that of separate purchases, attracting numerous consumers who previously had strong demand for one program to order the bundle.

TABle III. TABle 3. Suggested Prices for Microsoft Software Suites, October 1993. [2]

\begin{tabular}{|l|l|c|}
\hline \multirow{2}{*}{ Type of Program } & \multicolumn{2}{|c|}{ Microsoft Microsoft Office } \\
\cline { 2 - 3 } & \multicolumn{1}{|c|}{ Name } & Suggested Price(\$) \\
\hline Spreadsheet & Excel & 495 \\
Wordprocessor & Word & 495 \\
Graphics & Powerpoint & 495 \\
Database & Access & 495 \\
Other & Microsoft Mail & $80^{\mathrm{a}}$ \\
\hline Suite & (Electronic mail) & $750^{\mathrm{b}}$ \\
\hline
\end{tabular}

aNot usually sold separately; figure is license value.

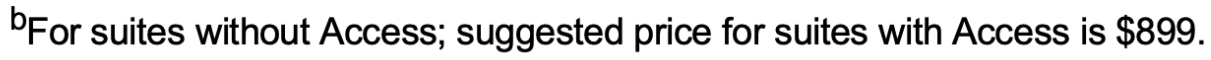


Since 1991, over $90 \%$ of the market share in the PC operating system business has been held by Microsoft, and it was estimated to possess $77 \%$ share of the software suite market in contrast to its major competitors, Lotus (18\%) and Borland-Word Perfect (the remaining 5\%). Price bundling contributed significantly to Microsoft ' $\mathrm{s}$ profitability, maintaining its dominant position in the operating system market [2].

3) Caveats: Several concerns exist for bundling. As a controversial legal issue, bundling might be viewed as an illegal practice since it sets barriers of entry for firms and reinforces their market power. Managers should therefore scrutinize their bundling designs' legality and provide essential benefits for consumers instead of overconcentrate on their short-run profitability. Furthermore, price bundling"yields larger profit increases the higher the relative contribution margin and the stronger economies of scale and scope are" [3], which indicates that it is most advantageous only when the bundled products with high development costs but low marginal costs.

\section{B.Two-Part Tariff}

1) Theory Explanation: Two-part tariff involves charging a lump-sum entry fee for all consumers and then charging a use fee for every additional unit consumed. It is a common practice in amusement parks, golf clubs, telecommunication companies, and car rentals. The required amount of payment is based on the quantity consumed by customers, thereby automatically differentiate low-demand customers from high-demand customers to obtain a larger part of consumer surplus.

Simple graphical analysis can provide some insights into this pricing method. Assuming the firm confronts constant marginal costs and identical linear demand curve for individuals, firms can represent the shaded area $\mathrm{B}$ as the previous maximized profit according to the $\mathrm{MC}=\mathrm{MR}$ rule. With a two-part tariff, firms can charge a per-unit use fee at marginal cost and an entry fee equal to the consumer surplus (Area of $\mathrm{A}+\mathrm{B}+\mathrm{C}$ ). Since no alteration to the profit is made by additional quantity sold, the firm's profit would now be the sum of the entry fee (Area of $\mathrm{A}+\mathrm{B}+\mathrm{C})$ in the market, and the entire consumer surplus is captured.

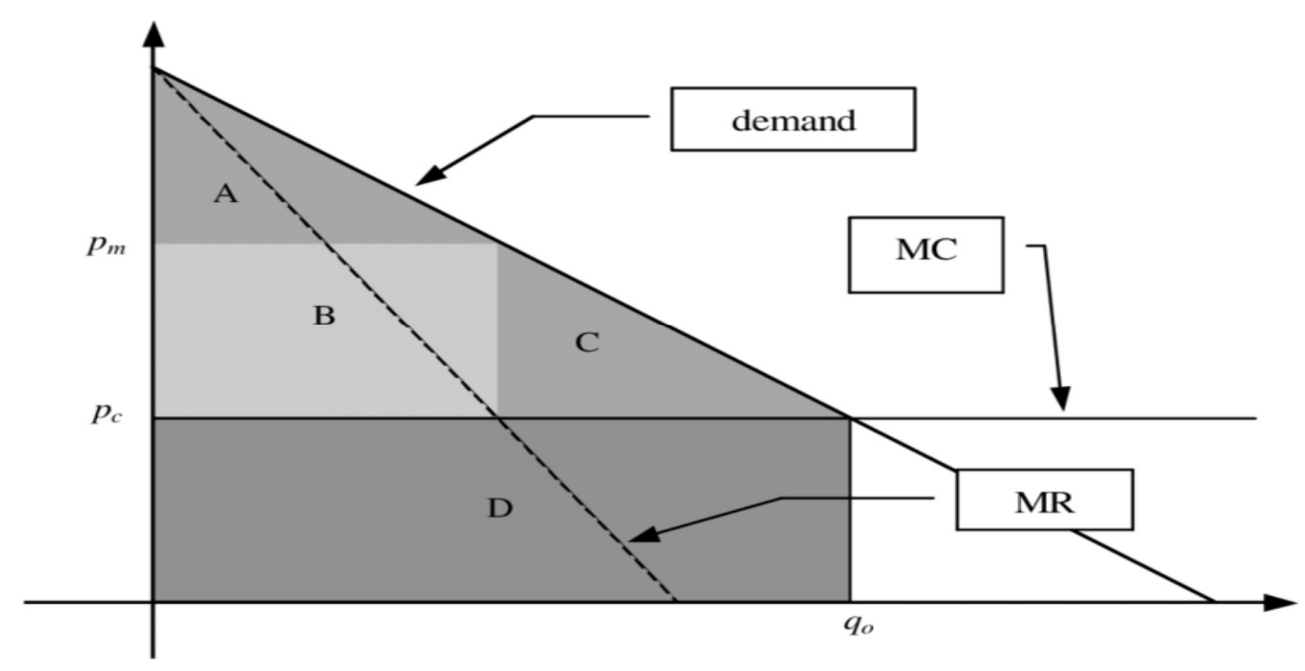

Figure 1. Two-part pricing when MC is constant [4]

2) Applications of Two-Part tariff in Personal Seat Licenses: Personal seat licenses are contractual agreements that entitle the licensee the right to purchase season tickets for a specific seat in the venue. [5] Adopting a two-part pricing mechanism, sport stadium managers require season ticket holders to purchase PSLs (the entry fee) to obtain the right to pay ticket prices (the use fee) for every single match. It is particularly prevalent in the American National Football League (NFL) that 19 out of 32 NFL teams have issued or plan to issue PSLs [6].

Due to the declined public subsidies for their expensive stadium construction costs that range from $\$ 2$ million to $\$ 2.6$ billion, teams are incentivized to provide PSLs as an approach to financing the costs and maintaining their profit levels. For instance, St. Louis Rams raised an extra $\$ 68$ million (Fig.2) by PSLs at an average price of $\$ 800$, which covered nearly $26 \%$ of the total construction costs. 


\begin{tabular}{ll}
\hline & St. Louis Rams \\
\hline Stadium construction costs & $\$ 260$ million \\
Stadium costs paid for by & State \\
Rent paid to state & $\$ 250,000 /$ year \\
PSL revenues & $\$ 68$ million \\
PSL revenues raised by & City \\
NFL relocation fee & $\$ 29$ million \\
NFL fee paid for with & PSL revenues \\
Other costs paid for with PSL & New training facility other moving \\
revenues & expenses $\$$ owed to Anaheim \\
\hline
\end{tabular}

Source: Steadman 1995a, 1995d; Stellino 1995b, 1995d; Preston 1995; LA Times 1994.

Figure 2. PSL Statistics for St. Louis Rams[5]

However, a significant limitation of two-part tariffs is reflected in PSL practices: sellers can severely underestimate the amount of consumer surplus. A majority of the teams shown in Figure 3 issue that PSLs with highest face-values are far lower than their highest resale prices, and demonstrate that consumers have considerably higher willingness to pay. Since the ardent sports fans have low price elasticities of demand for the stadium seats and PSLs could act as appreciating assets and financial instruments in the secondary markets, underpriced PSLs don' $t$ unlock the full potential of profitability for these teams.

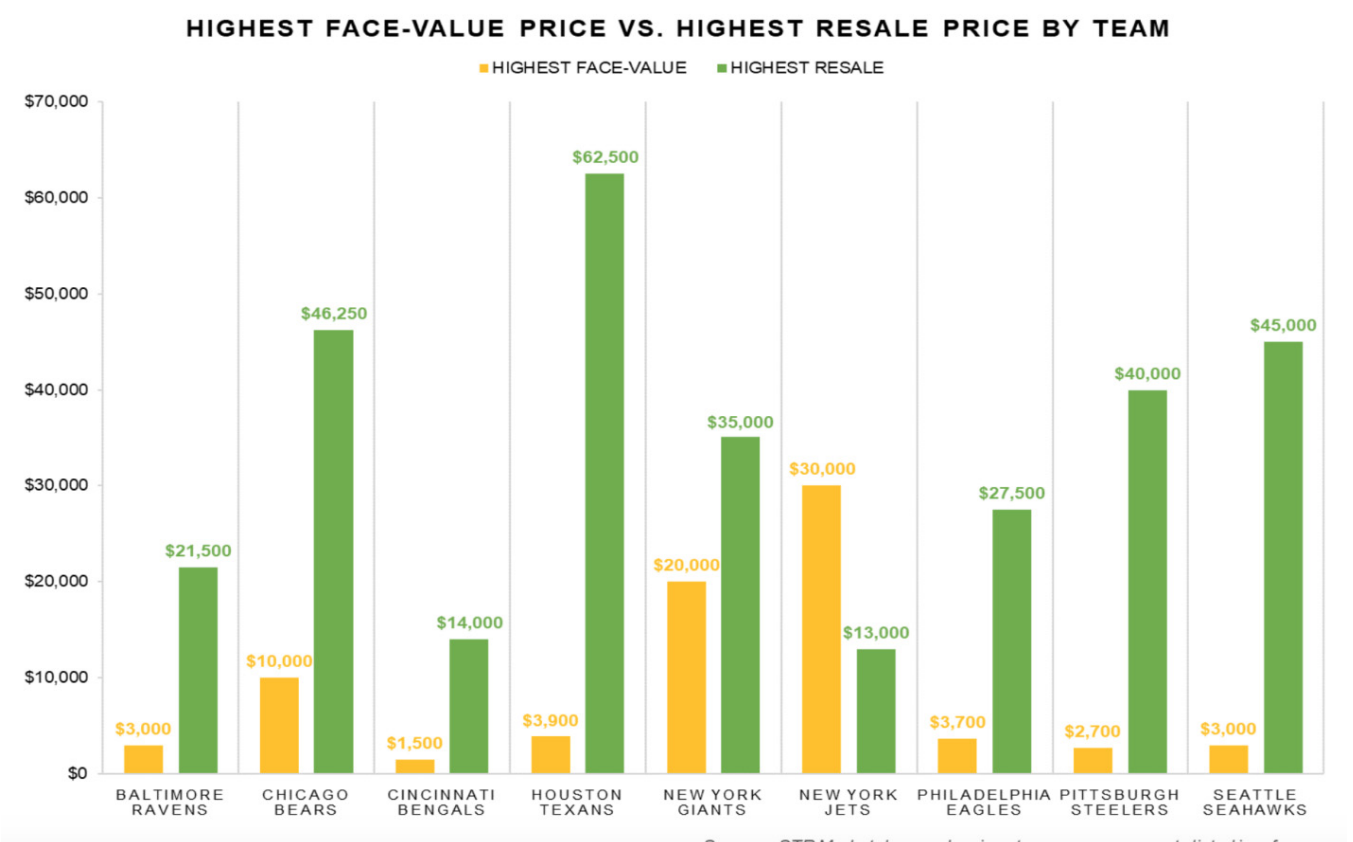

Figure 3. Comparisons between the highest face-value prices and highest resale prices of PSLs from different teams[6]

\section{C.Price Segmentation}

1)Theory Explanation: Price segmentation, or commonly known as segmenting the market, is an approach to identify sub-groups of a broad market and charge different prices based on their distinct price elasticity of demand while providing virtually homogeneous products or services. For instance, most of the tourist attractions offer discounts to specific groups like the children and the old, colleges charge higher fees for international students and counselors may require higher amounts of payment from the wealthy than from the poo. These are all real-life scenarios of price segmentation. The motivation for firms to adopt price segmentation instead of a single price could be explained graphically. 


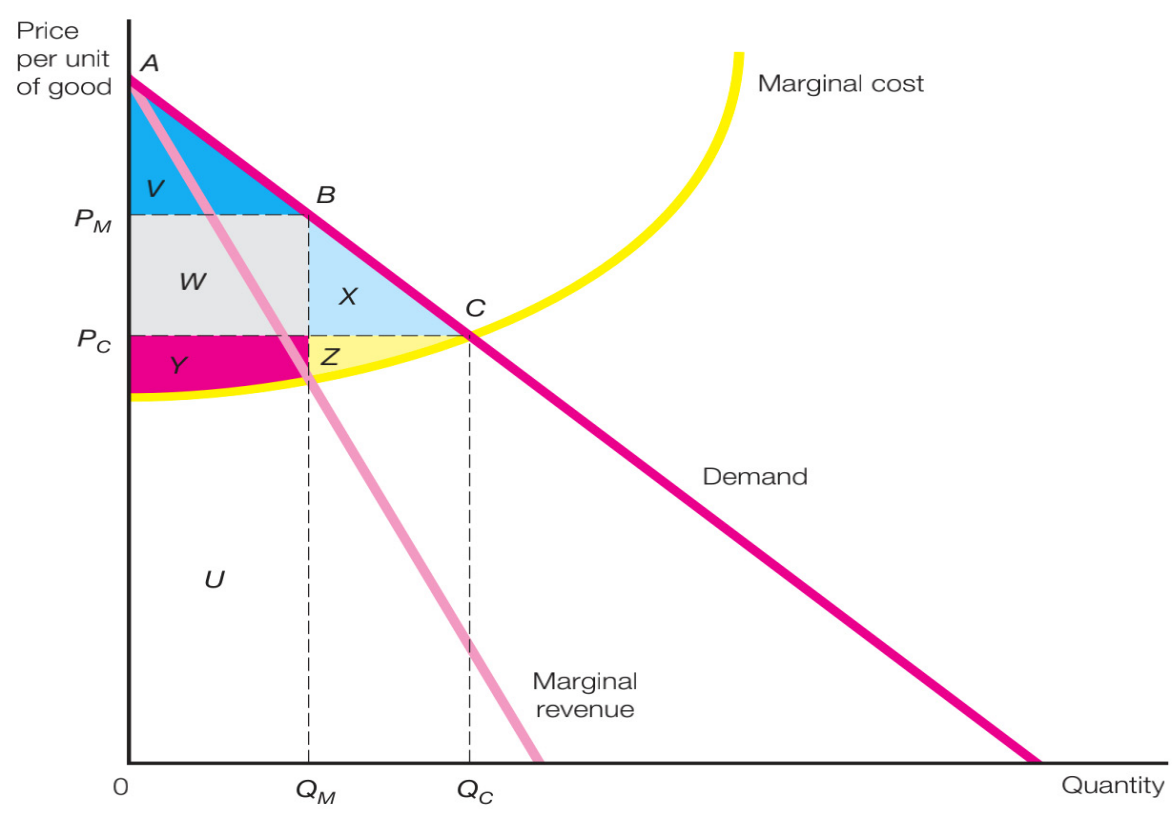

Figure 4. Demand curve, marginal revenue curve and marginal cost curve for an individual firm in an imperfectly competitive market[1]

Generally, firms with an objective of profit maximization choose to produce the quantity $\mathrm{QM}$ at which marginal cost equals to the marginal revenue (for any additional quantity produced the additional cost will outweigh the additional revenue, which will curtail the total profit) and select the corresponding price PM on the demand curve. The area of $\mathrm{W}+\mathrm{Y}$ represents the profit that the firm earns assuming no fixed costs are incurred. However, the demand curve demonstrates that existing consumers in range $\mathrm{AB}$ may have a larger extent of willingness to pay than $\mathrm{PM}$, and there are still potential consumers in range $\mathrm{BC}$ prepared to pay prices lower than PM but higher than the firm's marginal costs. Consequently, charging a single price would generate a loss up to area $\mathrm{V}+\mathrm{X}+\mathrm{Z}$ which could be partially acquired by price segmentation, making itself less favorable.
In Managerial Economics, price segmentation can be generalized as a ramification of third-degree price discrimination, which is the most common form of price discrimination, in which different groups of people pay different levels of prices regardless of the amount sold. By constructing demand curves for high-demand groups (D2) and low-demand groups (D1) separately, their respective marginal revenue curves are derived and the total MR curve G. As the profit-maximizing output level $\mathrm{Q}$ is determined, the appropriate prices are set for different consumer groups, achieving successful price segmentation. But in real-life, price segmentation can be much more complicated than this simple case which assumes that the number of segments is two.

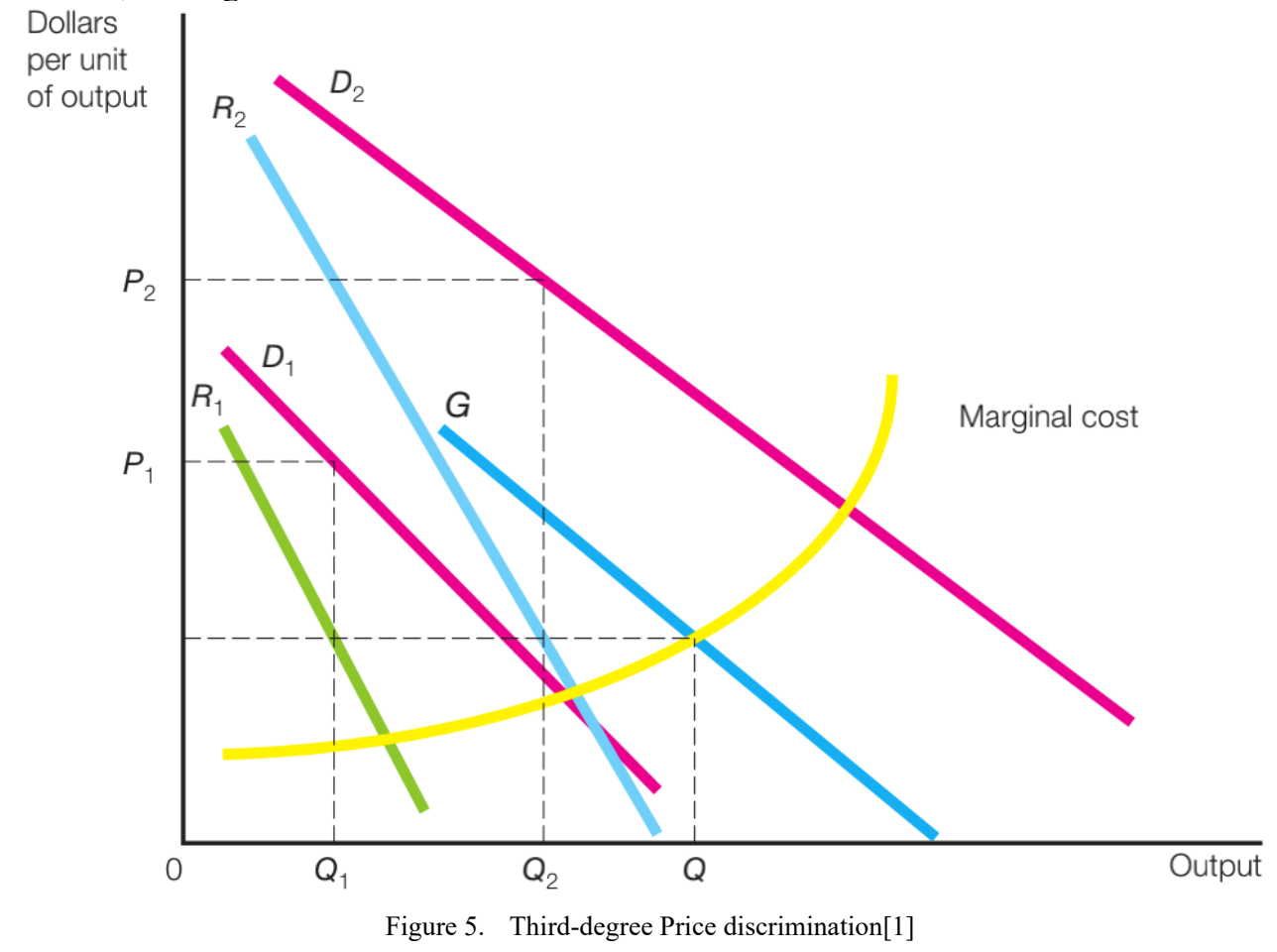


2)Applications of Price Segmentation in Broadway Theatre: Broadway theater refers to the theatrical performances presented in the 41 professional theatres located in Manhattan, New York City. Unlike other regulated theaters, the primary objective of Broadway is profit-maximization, allowing it to adopt various price segmentation methods for a particular play Seven Guitars.

In the first place, Broadway offers conditional discount prices to people who are willing to incur an intangible cost of queueing. Next, it prices the tickets for different time-series differently (selling at a higher price on Saturday evening than on Sunday, for example), which follows a peak-load pricing measure due to temporary demand differences. Additionally, the managers divides the seats into two regions of separate qualities which facilitates them to charge a higher price on audiences with insensitive demand. Those practices effectively supports Broadway to differentiate different consumer groups, and studies show that the price segmentation approaches escalates the firm' s profit by $5 \%$ relative to an optimal uniform pricing strategy.[7]

3) Caveats: Although the benefits of price segmentation to firms are significant, potential limitations of price discrimination still demand serious attention. To begin with, there are several indispensable conditions for successful price segmentation: the market must be segmentable, different segments must have distinct price elasticities of demand, and resale must be precluded from one buyer to another. In addition, fairness concerns among consumers may instigate protests which are detrimental to firms' reputations.

Potential government regulations may also prohibit unfair price segmentation to restrict firms' market power. As a result, the optimum price segmentation schemes for firms must take market environments and ethical issues into account.

\section{ConClusion}

Using Managerial Economics' ideas and analysis methods, firms can effectively design sophisticated pricing strategies in order to enhance their profitability and achieve business objectives. With price bundling, firms can utilize negative correlations in consumer demand and boost the sales revenue of a combination of products; with two-part tariffs, firms can extract a larger proportion of consumer surplus and increase the overall revenues and profits of themselves; With price segmentation, firms are capable of differentiating consumers with different price sensitivities and acquiring potential revenues from consumers with higher reservation prices. For companies that possess market power, those are certainly favorable alternatives for simple cost-plus pricing.
Nevertheless, business managers should be aware of the limitations of these theories. The theoretical assumptions made might be invalid in practical scenarios, so it is impossible to achieve the ideal of profit-maximization. Incomplete or inaccurate cost \& demand information also hinders business from charging theoretically optimum prices. Apart from that, the pricing strategies mentioned above all involve price discrimination to some extent. Therefore, instead of purely exploiting customers, firms need to set reasonable prices and offer true benefits to maintain their reputations that reflect their long-term profitability.

In conclusion, when choosing and designing optimal pricing strategies, managers should collect accurate demand information and carefully assess the social circumstances pertaining to the sales of the products. Successful pricing strategies will truly be the outcome of these Managerial Economics approaches if managers understand the rationales of these theories and make sensible adjustments for practical concerns.

\section{ACKNOWLEDGMENT}

My deep appreciation first goes to Professor Frank Litchenberg and his Teaching Assistant Anna, who provided me with academic support on the Managerial Economics Theories. I am also grateful to my essay instructors who offered important advice on the structure and delivery of this article.

\section{REFERENCES}

[1] Allen, B., Doherty, A., Weigelt K., Mansfield, E. (2013) Managerial Economics, Theory, Application and Cases, 8th edition, W. W. Norton \& Company, Inc, New York.

[2] Harvard Business School (1991), Bundling. https://store.hbr.org/product/bundling/191177?fromSku=W1754 8\&ab=store_idp_cabpanel_-_bundling_191177

[3] Stremersch, S., \& Tellis, G. (2002). Strategic Bundling of Products and Prices: A New Synthesis for Marketing. Journal of Marketing, 66(1), 55-72. Retrieved August 10, 2020, from www.jstor.org/stable/3203369

[4] https://www.researchgate.net/figure/Monopoly-pricing-optionsin-partial-equilibrium_fig1_23696718

[5] Bramlett, D., \& Sloan, M.(2000) The Commodification of Sports: The Example of Personal Seat Licenses in Professional Football. Rowman \& Littlefield Publishers, Inc., Maryland. pp. 177-202.

[6] Esther Chao (2018) Personal Seat Licenses: Who's Winning this Round of the Stadium Financing Game?https://www.stern.nyu.edu/sites/default/files/assets/docu ments/Esther\%20Chao_Thesis_NYUNY\%20Honors\%202018.p df

[7] Leslie, P. (2004). Price Discrimination in Broadway Theater. The RAND Journal of Economics, 35(3), 520-541. Retrieved August 14, 2020, from www.jstor.org/stable/1593706 